\title{
May predictors of difficulty in thyroid surgery increase the incidence of complications? Prospective study with the proposal of a preoperative score
}

Valerio D'Orazi ${ }^{1,2^{*+}} \mathbb{D}$, Andrea Sacconi ${ }^{3 \dagger}$, Silvia Trombetta ${ }^{2+}$, Menelaos Karpathiotakis ${ }^{1,2}$, Daniele Pichelli ${ }^{2}$, Enrico Di Lorenzo ${ }^{2,4}$, Alice Ortensi ${ }^{2,5}$, Paolo Urciuoli ${ }^{1}$, Marco Biffoni ${ }^{1}$ and Andrea Ortensi ${ }^{2,6}$

\begin{abstract}
Background: Although thyroidectomy is one of the most common surgical procedures performed worldwide, some permanent complications, despite the considerably reducing incidence, may affect dramatically the patients quality of life. The purpose of this study is to evaluate whether factors identified preoperatively and expressed in a score could be predictors of major surgical difficulty during total thyroidectomy and influence the incidence of complications.

Methods: A total of 164 patients who underwent total thyroidectomy were examined. For each patient we calculated a preoperative score, including seven parameters, which we evaluated to be predictors of difficulty in thyroid surgery, that is, sex, body mass index (BMI), neck length, neck extension, thyroid gland volume, thyroiditis, and increased parenchymal vascularization. The overall score was also compared with peri- and post-operative factors describing objectively the difficulty in thyroid surgery. These factors are the duration of the operation, the length of hospitalization, the incidence of complications such as hemorrhage, hypoparathyroidism, and recurrent laryngeal nerve injuries.

Results: There was no statistically significant association between our score and either the percentage of postoperative complications or the length of hospitalization. The operative time was the only variable remarkably associated with the score value $(p<0.00001)$. Comparing the duration of the operation with each of the preoperative predictive factors, we found that none of the factors reached the value of statistical significance, but a close association could be noted with the thyroid volume and the BMI.

Conclusions: In our study, predictors of difficulty in thyroidectomy did not affect morbidity rates, as suggested by previous studies, but only operative times, which were significantly increased in patients with higher score. Although our results have limited statistical significance, they allow us to confirm the fundamental role of a systematic use of optical magnification and microsurgical technique in thyroidectomy. Further studies, with a larger cohort of patients, are needed to validate our results and to formulate a universally accepted predictive score of difficulty in thyroidectomy preoperatively.
\end{abstract}

Keywords: Thyroid surgery, Difficult thyroidectomy, Predictive factors, Preoperative difficulty score

\footnotetext{
*Correspondence: valerio.dorazi@uniroma1.it

${ }^{\dagger}$ Valerio D'Orazi, Andrea Sacconi and Silvia Trombetta contributed equally to this work.

'Department of Surgical Sciences, "Sapienza" University, Viale Regina Elena

324, 00161, Rome, Italy

2Department of General Microsurgery and Hand Surgery, "Fabia Mater"

Hospital, Rome, Italy

Full list of author information is available at the end of the article
}

(c) The Author(s). 2019 Open Access This article is distributed under the terms of the Creative Commons Attribution 4.0 International License (http://creativecommons.org/licenses/by/4.0/), which permits unrestricted use, distribution, and reproduction in any medium, provided you give appropriate credit to the original author(s) and the source, provide a link to the Creative Commons license, and indicate if changes were made. The Creative Commons Public Domain Dedication waiver (http://creativecommons.org/publicdomain/zero/1.0/) applies to the data made available in this article, unless otherwise stated. 


\section{Background}

Thyroidectomy is one of the most common surgical procedures performed worldwide. Over 34,000 operations were performed during 2016 in Italy and the incidence of thyroid diseases that require total thyroidectomy is constantly increasing [1].

Historically, mortality in thyroid surgery drastically reduced from about $50 \%$ in the dawn of the last century to a negligible rate nowadays, thanks to the improvement of surgical techniques, the introduction of technological innovations, and the improved knowledge of pathophysiology. Therefore, the incidence of perioperative complications is around $1-2 \%$ [2-4]. However, permanent complications, such as vocal cord palsy and hypoparathyroidism, can dramatically reduce the quality of life of patients and have always represented a topic of intense clinical interest and research for most neck surgeons.

The literature shows a strong evidence that the incidence of perioperative complications correlates to factors such as thyroid disease, specific characteristics of each patient or the thyroid gland, surgeon's experience and surgical technique, even with the use of optical magnification tools [5-11].

The purpose of our study was to evaluate whether preoperative factors, grouped into a score and predictive of major surgical difficulty in thyroidectomy, might influence the incidence of complications, in order to improve patient's management and optimize the planning of the operating theater.

\section{Methods}

For this prospective study, a database of 195 consecutive patients who underwent total thyroidectomy from 01/01/ 2015 to 30/06/2017 in our center was reviewed. All patients obtained written informed consent. Operations were performed by two experienced surgeons of the microsurgery team. Exclusion criteria were lobectomy, reoperative thyroidectomy, concomitant parathyroidectomy and lymph node dissection for malignancy. Therefore, a cohort of 164 patients who had total thyroidectomy was examined. The minimum follow-up period was 6 months.

For each patient, during the preoperative assessment, a score was calculated including the following seven parameters, which we evaluated to be predictors of difficulty in thyroid surgery: sex, body mass index (BMI; $\mathrm{Kg} / \mathrm{m}^{2}$ ), neck length $(\mathrm{cm})$, neck extension, thyroid gland volume $(\mathrm{ml})$, laboratory evidence of thyroiditis (high anti-Tg Ab levels), and Doppler-ultrasound evidence of increased parenchymal vascularization.

Routinely, all patients undergoing total thyroidectomy at our institution have a clinical assessment including thyroid function laboratory tests (dosage of free levels of T3 and T4, TSH, calcitonin, thyroglobulin-Tg, Ab anti-Tg, Ab anti-TPO), pre- and postoperative fibrolaringoscopy and thyroid Doppler ultrasonography. The radiologists provide us the value of the thyroid volume and the pattern of parenchymal vascularization.

The length of the neck was estimated by measuring the distance in $\mathrm{cm}$ between the jugular notch and the cricoid cartilage, considering a length of $6 \mathrm{~cm}$ as the lower threshold. The extensibility of the neck, evaluated preoperatively by the anesthesiologists, was distinguished in normal or reduced, regardless of the pathology (arthritis, cervical hernias, previous traumas, etc.).

Our surgical experience suggests that not all the risk factors identified preoperatively affect the difficulty of the surgical procedure equally. Thus, we decided to assign a different value in each of these parameters based on the empirical relevance they could have regarding the grade of surgical difficulty. Once established and calculated the individual value for each of the parameters, we formulated the overall score, with a range of values from 0 to 15 .

To stratify the obtained results, we identified three groups: patients with a low score (0-3), medium score (4-5), and high score $(\geq 6)$ (Table 1$)$.

The overall score was also compared with peri- and post-operative factors describing objectively the difficulty encountered during surgery. These factors are the duration of the operation, the length of hospitalization, the incidence of complications such as hemorrhage, hypoparathyroidism, and recurrent laryngeal nerve (RLN) injuries, either transient or permanent. The duration of the operation was obtained from the electronic operative register. Hypoparathyroidism was defined as the need for supplementary therapy with calcium and vitamin D. RLN injury was documented by postoperative fibrolaringoscopy, which is

Table 1 Preoperative parameters and score calculation

\begin{tabular}{lll}
\hline Sex & Female & 0 \\
BMI $\left(\mathrm{kg} / \mathrm{m}^{2}\right)$ & Male & 1 \\
& $<30$ & 0 \\
Neck length $(\mathrm{cm})$ & $\geq 30$ & 1 \\
Neck extensibility $(\mathrm{cm})$ & $\geq 6 \mathrm{~cm}$ & 0 \\
& $<6 \mathrm{~cm}$ & 2 \\
Thyroid volume $(\mathrm{ml})$ & Normal & 0 \\
& Reduced & 2 \\
Hypervascularization & $\leq 80 \mathrm{ml}$ & 0 \\
Thyroiditis & $>80 \mathrm{ml}$ & 3 \\
& No & 0 \\
Score level & Yes & 3 \\
& No & 0 \\
& Yes & 3 \\
& Low & $0-3$ \\
& Medium & $4-5$ \\
& High & $6-15$ \\
\hline
\end{tabular}


usually performed about 20 days after surgery. Complications were defined as transient in the event of complete resolution within 6 months from surgery, otherwise they were considered permanent.

The aim of our study was to compare the score of the population with all the peri- and post-operative parameters above mentioned, in order to understand whether the suggested model could be useful and reliable to predict the difficulty of thyroidectomy.

Statistical significance of the association between score level and categorical variables was assessed by using a Chi-square test.

\section{Surgical technique}

All patients included in the study underwent total extracapsular thyroidectomy, in microsurgical technique using 4,5X loupes magnification by two experienced neck surgeons. We performed a Kocher incision of about $6 \mathrm{~cm}$. After dissection of the superior and inferior subplatysmal flap, the strap muscles were divided longitudinally in the midline and the thyroid lobe was exposed and medially dislocated, once the middle thyroid vein was divided. We proceeded with the dissection of the superior pole, by separated ligation and division of the two branches of the superior thyroid artery, identifying and preserving the upper parathyroid and the motor branch of the superior laryngeal nerve. The ipsilateral RLN was identified with digital technique, traced along its entire cervical course, up to the entrance in the larynx. The distal branches of the inferior thyroid artery were divided, identifying and preserving the inferior parathyroid gland with its vascular peduncle. The same procedure was performed for the contralateral lobe, completing the thyroidectomy by removing the pyramidal lobe. Hemostasis was performed using bipolar electrocautery and microsurgical ligatures. The cervicotomy was closed after placement of two suction drains. In our Department, the use of ultrasound and radiofrequency devices for coagulation and tissue dissection is well established.

\section{Results}

A population of 164 patients who underwent total extracapsular thyroidectomy in microsurgical technique was included in the study. Patients' demographics, clinical and preoperative features and score values are summarized in Table 2. Post-operative data and outcomes are summarized in Table 3 . Table 4 shows the statistical correlation through Chi-square test among the score level and the postoperative variables. We considered statistically significant values of $p<0.001$. Complications were considered as a whole and individually. No permanent hypoparathyroidism or RLN injury have been reported. About the length of hospitalization, we identified two groups of patients, accepting 2 days as the normal stay.
Table 2 Demographic and pathophysiological characteristics of the population and overall score

\begin{tabular}{|c|c|c|}
\hline $\begin{array}{l}\text { Period of study } \\
\text { Jan } 2015 \text { - July } 2017\end{array}$ & Number & Percentage (\%) \\
\hline Patients & 164 & \\
\hline \multicolumn{3}{|l|}{ Sex } \\
\hline - Female & 135 & 82.3 \\
\hline - Male & 29 & 17.7 \\
\hline \multicolumn{3}{|l|}{ Age } \\
\hline - Range & $21-79$ & \\
\hline - Average & 54.0 & \\
\hline \multicolumn{3}{|l|}{ BMI $\left(\mathrm{Kg} / \mathrm{m}^{2}\right)$} \\
\hline - $<30$ & 131 & 79.9 \\
\hline - $\geq 30$ & 33 & 20.1 \\
\hline - Average & 26.1 & \\
\hline \multicolumn{3}{|l|}{ Neck length (cm) } \\
\hline - $\geq 6 \mathrm{~cm}$ & 150 & 91.5 \\
\hline - $<6 \mathrm{~cm}$ & 14 & 8.5 \\
\hline \multicolumn{3}{|l|}{ Neck extensibility (cm) } \\
\hline - Normal & 144 & 87.8 \\
\hline - Reduced & 20 & 12.2 \\
\hline \multicolumn{3}{|l|}{ Diagnosis } \\
\hline - Goiter & 87 & 53.0 \\
\hline - Hyperthyroidism & 17 & 10.4 \\
\hline - Tir3A & 10 & 6.1 \\
\hline - Tir3B & 30 & 18.3 \\
\hline - Tir4 & 14 & 8.5 \\
\hline - Tir5 & 6 & 3.7 \\
\hline \multicolumn{3}{|l|}{ Thyroid volume (ml) } \\
\hline - $\leq 80 \mathrm{ml}$ & 130 & 79.3 \\
\hline - $>80 \mathrm{ml}$ & 34 & 20.7 \\
\hline \multicolumn{3}{|l|}{ Hypervascularization } \\
\hline - No & 116 & 70.7 \\
\hline - Yes & 48 & 29.3 \\
\hline \multicolumn{3}{|l|}{ Thyroiditis } \\
\hline - No & 111 & 67.7 \\
\hline - Yes & 53 & 32.3 \\
\hline \multicolumn{3}{|l|}{ Overall score level } \\
\hline - Low & 115 & 70.1 \\
\hline - Medium & 19 & 11.6 \\
\hline - High & 30 & 18.3 \\
\hline
\end{tabular}

Regarding the duration of surgery, patients were divided into two groups according to the median of $95 \mathrm{~min}$.

The results showed no statistical significant association between our score and either the percentage of postoperative complications or the length of hospitalization. The operative time was the only variable remarkably 
Table 3 Peri- and postoperative parameters and surgical outcomes

\begin{tabular}{|c|c|c|}
\hline Histology & Number & $\begin{array}{l}\text { Percentage } \\
(\%)\end{array}$ \\
\hline - Hyperplasia & 60 & 36.6 \\
\hline - Thyroiditis & 3 & 1.8 \\
\hline - Multinodular goiter & 8 & 4.9 \\
\hline - Follicular adenoma & 15 & 9.1 \\
\hline - FT-UMPa & 1 & 0.6 \\
\hline - Malignancy: & 77 & 46.9 \\
\hline Papillary ca n.o.s. & 31 & 40.2 \\
\hline Papillary ca follicular variant & 38 & 49.3 \\
\hline Papillary ca oncocitary variant & 2 & 2.6 \\
\hline Papillary ca sclerosing variant & 2 & 2.6 \\
\hline Follicular ca & 2 & 2.6 \\
\hline Medullary ca & 2 & 2.6 \\
\hline \multicolumn{3}{|l|}{ Duration of the operation (min) } \\
\hline - Average & 104.4 & \\
\hline - Median & 95 & \\
\hline - Range & $50-250$ & \\
\hline \multicolumn{3}{|l|}{ Length of hospitalization (d) } \\
\hline - Average & 2.46 & \\
\hline - 2 days & 108 & 65.9 \\
\hline - $>2$ days & 56 & 34.1 \\
\hline \multicolumn{3}{|l|}{ Complications } \\
\hline - Hemorrhage & 3 & 1.8 \\
\hline - Hypoparathyroidism (transient) & 28 & 17.1 \\
\hline - Hypoparathyroidism (permanent) & 0 & / \\
\hline $\begin{array}{l}\text { - Recurrent laryngeal nerve lesion } \\
\text { (transient) }\end{array}$ & 1 & 0.6 \\
\hline $\begin{array}{l}\text { - Recurrent laryngeal nerve lesion } \\
\text { (permanent) }\end{array}$ & 0 & / \\
\hline
\end{tabular}

${ }^{a}$ FT-UMP follicular tumor of uncertain malignant potential

associated with the score value $(p<0.00001)$. The association was even more significant if the groups of medium and high score level were combined $(p<0.000002)$.

Hence, we compared the duration of the operation with each of the preoperative predictors used for the score calculation to evaluate if any of these was more responsible for the correlation (Table 5). None of the factors reached the value of statistical significance, however a close association could be noted with the thyroid volume and the BMI ( $p=0.0016$ and 0.009 respectively).

\section{Discussion}

Throughout the literature is possible to find different examples of scores and scales proposed to evaluate preoperatively the difficulty of the surgical procedure and based on specific risk factors associated with the type of the operation (e.g. nephrectomy etc.) [12-16].

However, about thyroid surgery, there are only few results for scores or scales predictive of surgical difficulty, which are defined only intra- or postoperatively [5, 17-20]. To our knowledge, there is no preoperative score able to evaluate predictors of difficulty in total thyroidectomy and detect patients with higher risk of complications.

In this study we identified some preoperative predictors of major surgical difficulty and consequently of higher risk of complications. The parameters analyzed were sex, BMI, length and extensibility of the neck, thyroid volume, hypervascularization, and thyroiditis.

For each factor we assigned a value from 0 to 3 ; the sum of each category determined the final score. According with this score, we divided the study population into three groups: high, medium and low level of surgical risk. Subsequently, each group was correlated with the incidence of complications (hemorrhage, permanent or transient RLN injury, and permanent or transient hypoparathyroidism), with the duration of the operation and the length of hospitalization.

In our opinion, the predictive factors represent those characteristics of the patient or of the thyroid disease that can influence the difficulty of the surgery. The choice of these parameters was made in accordance with our surgical experience and the existing scores.

For example, neck surgeons agree that certain thyroid disorders (thyroiditis, hyperthyroidism) are associated with pathophysiological features of the gland that can make the dissection quite difficult [21-23], as well as some more aggressive thyroid tumors [24-26]. There is even the possibility that some thyroid tumors can metastasize to the contralateral axillary lymph nodes, and in such cases it is important to make a differential diagnosis with a breast cancer lymph node metastasis [27]. Furthermore, extended lymph node dissections in patients with thyroid cancer may be more challenging and high-risk than simple thyroidectomies; however, there is no evidence in the literature that they can significantly increase the complication rates [28-33].

Our decision to evaluate the length and the extensibility of the neck as predictive factors of difficulty was empiric and according with most of the neck surgeons that consider fundamental a satisfactory exposure of the surgical site. This can be achieved with hyperextension of the neck and eventually interposition of a support between the table and patient's shoulder blades. Reasonably, in patients with short or inflexible neck the surgeon may experience greater difficulty during surgery because of a restricted operating field.

Kwak et al. [18] in 2017 suggested a score, graded after surgery, identifying the duration of the operation as a factor of surgical difficulty in thyroidectomy. Although 
Table 4 Correlations among score level and categorical perioperative variables $(p<0.001)$

\begin{tabular}{|c|c|c|c|c|}
\hline & $\begin{array}{l}\text { Low risk } \\
\text { (115 pts) }\end{array}$ & $\begin{array}{l}\text { Medium risk } \\
(19 \text { pts) }\end{array}$ & $\begin{array}{l}\text { High risk } \\
(30 \text { pts) }\end{array}$ & $p$ value \\
\hline Complications & & & & 0.52 \\
\hline - No & 92 & 17 & 23 & \\
\hline - Yes & 23 & 2 & 7 & \\
\hline Hemorrhage & 1 & 0 & 2 & \\
\hline Hypoparathyroidism & 21 & 2 & 5 & \\
\hline RLN lesion & 1 & 0 & 0 & \\
\hline Length of hospitalization & & & & 0.85 \\
\hline - 2 days & 75 & 12 & 21 & \\
\hline - $>2$ days & 40 & 7 & 9 & \\
\hline Duration of the operation & & & & 0.00001 \\
\hline - $\leq 95 \min$ & 72 & 6 & 5 & \\
\hline \multirow[t]{2}{*}{ - $>95 \min$} & 43 & 13 & 25 & \\
\hline & $\begin{array}{l}\text { Low risk } \\
\text { (115 pts) }\end{array}$ & & Medium/high risk (49 pts) & \\
\hline Duration of the operation & & & & 0.000002 \\
\hline - $\leq 95 \min$ & 72 & & 11 & \\
\hline - $>95 \mathrm{~min}$ & 43 & & 38 & \\
\hline
\end{tabular}

Table 5 Correlation between duration of the operation and each of the variables used for score calculation

\begin{tabular}{|c|c|c|c|}
\hline & $\begin{array}{l}\text { Operative times } \\
\leq 95 \mathrm{~min} \text { (83 pts) }\end{array}$ & $\begin{array}{l}\text { Operative times } \\
>95 \mathrm{~min} \text { (81 pts) }\end{array}$ & $p$ value \\
\hline Sex & & & 0.055 \\
\hline - Female & 73 & 62 & \\
\hline - Male & 10 & 19 & \\
\hline BMI $\left(\mathrm{Kg} / \mathrm{m}^{2}\right)$ & & & 0.009 \\
\hline - $<30$ & 73 & 58 & \\
\hline - $\geq 30$ & 10 & 23 & \\
\hline Neck length (cm) & & & 0.96 \\
\hline - $\geq 6 \mathrm{~cm}$ & 76 & 74 & \\
\hline - $<6 \mathrm{~cm}$ & 7 & 7 & \\
\hline Neck extensibility & & & 0.14 \\
\hline - Normal & 76 & 68 & \\
\hline - Reduced & 7 & 13 & \\
\hline Thyroid volume & & & 0.0016 \\
\hline - $\leq 80 \mathrm{ml}$ & 74 & 56 & \\
\hline - $>80 \mathrm{ml}$ & 9 & 25 & \\
\hline Hypervascularization & & & 0.012 \\
\hline - No & 66 & 50 & \\
\hline - Yes & 17 & 31 & \\
\hline Thyroiditis & & & 0.95 \\
\hline - No & 56 & 55 & \\
\hline - Yes & 27 & 26 & \\
\hline
\end{tabular}


they demonstrated that the young age and the male sex are predictive factors of difficult thyroidectomy in terms of operative times, the incidence of complications is not statistically higher in the group of potentially difficult thyroidectomies. The results are comparable to those of previous studies reporting that a higher BMI could be considered a predictive factor of longer operating times and higher morbidity [34]; other Authors suggested that neck circumference, instead of BMI, might be correlated with the duration of the operation as a predictor of difficulty [19].

In 2014 Schneider et al. [5] proposed a Thyroidectomy Difficulty Scale (TDS) based on postoperative evaluation of four parameters (vascularization, friability, fibrosis and gland size) in order to predict the surgical difficulty. After analysis of the data, they observed that increased vascularization of the thyroid gland is more correlated to hyperthyroidism, similarly with the presence of thyroiditis that influences the development of parenchymal fibrosis. The Authors concluded that high scores were correlated with longer operative times and higher risk of complications.

Subsequently, Mok et al. [17] compared the variables used for the TDS with the pathological features of the population and underlined that patients with hyperthyroidism, high levels of thyroglobulin and positivity for anti-thyroglobulin antibodies showed a higher overall score, therefore, were subjects of major risk of complications.

In the present study, the incidence of complications was negligible with quite homogeneous distribution among the three groups of patients. No permanent hypoparathyroidism or RLN injury have been reported. Thus, we can argue that the predictive factors of difficulty in thyroidectomy identified by our score did not affect the rate of complications, contrarily to previous studies [5, 17]. Even analysis of the data regarding the length of hospitalization did not show statistical correlation with our score (Table 4).

However, the results related to the operative times were different; there is strong evidence that a higher score level correlates with longer duration of the operation and therefore with an increased complexity of the surgical procedure (Table 4). Nevertheless, no association was shown in our series between the rate of perioperative complications and the complexity or duration of the operation. We strongly believe that total thyroidectomy performed by experienced surgeons with microsurgical technique under optical magnification permits to significantly reduce the incidence of permanent hypoparathyroidism and RLN lesions, as already demonstrated in our previous studies and confirmed by numerous evidences in the literature [35-40].

The current study has some limitations. Firstly, the subjective criteria in the definition of preoperative parameters as risk factors and secondly the empirically estimated threshold values, or even the absence of intermediate values in the categorical variables suggested for the score calculation. However, this has been done intentionally in order to make the score more intuitive and, therefore, easier to calculate. Finally, the number of patients who composed our study group from a single institution is certainly too low to obtain universally consolidated results.

Despite the limitations, we must recognize some strengths of this study; it is a prospective study, based on data collected directly during the clinical assessment of each patient and not through the medical records. Our thyroidectomy difficulty score is the only one existing in the literature than was formulated exclusively in accordance with preoperative parameters. The intention was to provide the surgeons with a valid tool to predict difficulty in thyroidectomy and to identify the patients at risk of complications. Moreover, this information could be useful to improve the informed consent counseling and the operating theatre planning. Finally, the parameters considered as predictors of difficulty, were heterogeneous and therefore more complete: some concerned the demographic characteristics of the patient, others their anatomo-pathological features, others the characteristics of the thyroid gland.

Further studies, with a larger cohort of patients, are needed to validate our results and to formulate a universally-accepted preoperative predictive score of difficulty in thyroid surgery.

\section{Conclusions}

The comparison among the groups of patients who underwent total extracapsular thyroidectomy with microsurgical technique, defined preoperatively by the score as low, medium and high risk of complications, allowed us to make some interesting considerations regarding the incidence of complication, such as RLN injuries and hypoparathyroidism, either transient or permanent.

Our data revealed that these complications, besides negligible and always transitory, are distributed quite homogeneously among the subgroups of patients, so we can conclude that the predictors of difficulty in thyroidectomy are not correlated with morbidity rates, as contrary suggested by previous studies, but only with operative times, which were significantly increased in patients with higher score.

Although our results have limited statistical significance, they support our belief in the fundamental role of the microsurgical technique in thyroid surgery, as a valuable instrument to recognize and overcome any foreseeable or unexpected difficulties and to maintain the percentage of complications insignificant. 
In addition, the prediction of a difficult thyroidectomy may be helpful for less experienced surgeons to increase the level of attention, especially in complex situations.

The results of our study could be useful not only to predict the difficulty of a total thyroidectomy but also to optimize the schedule of the operating room, reduce the costs and improve the management of the patients and the available resources.

\section{Abbreviations}

BMI: body mass index; RLN: recurrent laryngeal nerve; TDS: thyroidectomy difficulty scale

\section{Acknowledgments}

The authors thank Gabriella D'Orazi for critical reading of the manuscript. The authors are also very grateful for the support by Guarnieri family, owner of "Fabia Mater" Hospital, anesthesiologists and nursing staff.

\section{Funding}

The publication of this article was supported by grant Miur FFABR.

\section{Availability of data and materials}

The dataset used during the current study is available from the corresponding author on reasonable request.

\section{About this supplement}

This article has been published as part of BMC Surgery Volume 18 Supplement 1, 2018: Updates and New Technology in Endocrine Surgery. The full contents of the supplement are available online at https:// bmcsurg.biomedcentral.com/articles/supplements/volume-18supplement-1.

\section{Authors' contributions}

VD, ST, DP, MB and MK participated substantially in conception, design, and execution of the study. VD and AO performed surgery. EDL performed pre and post-operative phoniatric and speech evaluation. AlO performed neck physiotherapy. AS performed statistical analysis, interpretation of data and the final assessment of the paper. MK, ST, DP, MB and PU performed the literature search, data acquisition and participated substantially in the drafting and editing of the manuscript. All the authors helped prepare the manuscript and approved of the final version.

VD, AS and ST contributed equally to this work.

All authors read and approved the final manuscript.

\section{Ethics approval and consent to participate}

The study was approved by the local ethics committee of "Fabia Mater" Hospital, Rome, Italy. Written informed consent was obtained from the patients for surgery and publication of this manuscript. A copy of written consent is available for review by the Editor-in-Chief of this Journal.

\section{Consent for publication}

Written informed consent was obtained from the patients involved in the study.

\section{Competing interests}

The authors declare that they have no competing interests.

\section{Publisher's Note}

Springer Nature remains neutral with regard to jurisdictional claims in published maps and institutional affiliations.

\section{Author details}

'Department of Surgical Sciences, "Sapienza" University, Viale Regina Elena 324, 00161, Rome, Italy. 'Department of General Microsurgery and Hand Surgery, "Fabia Mater" Hospital, Rome, Italy. ${ }^{3}$ Translational Oncogenomics Unit, Molecular Medicine Area, "Regina Elena" National Cancer Institute, Rome, Italy. ${ }^{4}$ Department of General Microsurgery and Hand, Surgery Section of phoniatrics and speech therapy, "Fabia Mater" Hospital, Rome, Italy.
${ }^{5}$ Department of General Microsurgery and Hand Surgery, Section of physiotherapy, "Fabia Mater" Hospital, Rome, Italy. ${ }^{6}$ Chief of Department of General Microsurgery and Hand Surgery, "Fabia Mater" Hospital, Rome, Italy.

Received: 24 September 2018 Accepted: 15 November 2018 Published: 24 April 2019

\section{References}

1. Italian Ministry of Health, Annu Rep on hospital admissions, 2016. http:// www.salute.gov.it/portale/documentazione/p6_2_2_1.jsp?lingua= italiano\&id=2651 Accessed 10 Jan 2018.

2. Conzo G, Avenia N, Bellastella G, Candela G, De Bellis A, Esposito K, Pasquali $D$, Polistena A, Santini $L$, Sinisi AA. The role of surgery in the current management of differentiated thyroid cancer. Endocrine. 2014;47:380-8.

3. Giddings AE. The history of thyroidectomy. J R Soc Med. 1998; 91(Suppl 33):3-6.

4. Sosa JA, Bowman HM, Tielsch JM, Powe NR, Gordon TA, Udelsman R. The importance of surgeon experience for clinical and economic outcomes from thyroidectomy. Ann Surg. 1998;228:320-30

5. Schneider DF, Mazeh $\mathrm{H}$, Oltmann SC, Chen $\mathrm{H}$, Sippel RS. Novel thyroidectomy difficulty scale correlates with operative times. World J Surg. 2014:38:1984-9.

6. D'Orazi V, Panunzi A, Di Lorenzo E, Al O, Cialini M, Anichini S, Ortensi A. Use of loupes magnification and microsurgical technique in thyroid surgery: ten years experience in a single center. G Chir. 2016;37:101-7.

7. Nielsen TR, Andreassen UK, Brown CL, Balle VH, Thomsen J. Microsurgical technique in thyroid surgery. A 10-year experience. J Laryngol Otol. 1998; 112:556-60.

8. Seven H, Calis AB, Vural C, Turqut S. Microscopic thyroidectomy: a prospective controlled trial. Eur Arch Otorhinolaryngol. 2005;262:41-4.

9. Williams SP, Wilkie MD, Tahery J. Microscope-assisted thyroidectomy: our experience in one hundred and twenty-one consecutive cases. Clin Otolaryngol. 2014;39:289-315.

10. Testini M, Nacchiero M, Piccinni G, Portincasa P, Di Venere B, Lissidini G, Bonomo GM. Total thyroidectomy is improved by loupe magnification. Microsurgery. 2004;24:39-42

11. Duclos A, Peix JL, Colin C, Kraimps JL, Menegaux F, Pattou F, Sebag F, Touzet S, Bourdy S, Voirin N, Lifante JC. CATHY Study Group Influence of experience on performance of individual surgeons in thyroid surgery: prospective cross sectional multicentre study. BMJ. 2012;344:d8041.

12. Mathieu R, Verhoest G, Droupy S, de la Taille A, Bruyere F, Doumerc N, Rischmann P, Vaessen C, Roupret M, Bensalah K. Predictive factors of complications after robot-assisted laparoscopic partial nephrectomy: a retrospective multicentre study. BJU Int. 2013;112:E283-9.

13. Jamali FR, Soweid AM, Dimassi H, Bailey C, Leroy J, Marescaux J. Evaluating the degree of difficulty of laparoscopic colorectal surgery. Arch Surg. 2008; 143:762-7 discussion 768.

14. Ahanchi SS, Carroll M, Almaroof B, Panneton JM. Anatomic severity grading score predicts technical difficulty, early outcomes, and hospital resource utilization of endovascular aortic aneurysm repair. J Vasc Surg. 2011:54:1266-72.

15. Van Oldenrijk J, Schafroth MU, Rijk E, Runne WC, Verheyen CC, van Egmond C, Bhandari M, Poolman RW. Learning curve analysis of the collum femoris preserving total hip surgical technique. Hip Int. 2013;23:154-61.

16. Ye X, Hong X, Ni K, Teng X, Xie K. Preoperative factors predicting poor outcomes following laparoscopic choledochotomy: a multivariate analysis study. Can J Surg. 2013:56:227-32.

17. Mok VM, Oltmann SC, Chen H, Sippel RS, Schneider DF. Identifying predictors of a difficult thyroidectomy. J Surg Res. 2014;190:157-63.

18. Kwak HY, Dionigi G, Liu X, Sun H, Woo SU, Son GS, Lee JB, Bae JW, Kim HY. Predictive factors for longer operative times for thyroidectomy. Asian J Surg. 2017:40:139-44

19. Consorti F, Milazzo F, Notarangelo M, Scardella L, Antonaci A. Factors influencing the length of the incision and the operating time for total thyroidectomy. BMC Surg. 2012 Jul 31;12:15

20. Kwak HY, Kim HY, Lee HY, Jung SP, Woo SU, Son GS, Lee JB, Bae JW. Predictive factors for difficult robotic thyroidectomy using the bilateral axillo-breast approach. Head Neck. 2016:38(Suppl 1):E954-60.

21. Liu J, Sun W, Dong W, Wang Z, Zhang P, Zhang T, Zhang H. Risk factors for post-thyroidectomy haemorrhage: a meta-analysis. Eur J Endocrinol. 2017. 176:591-602. 
22. McManus C, Luo J, Sippel R, Chen H. Is thyroidectomy in patients with Hashimoto thyroiditis more risky? I Surg Res. 2012;178:529-32.

23. Shih ML, Lee JA, Hsieh CB, Yu JC, Liu HD, Kebebew E, Clark OH, Duh QY. Thyroidectomy for Hashimoto's thyroiditis: complications and associated cancers. Thyroid. 2008;18:729-34.

24. Grani G, Lamartina L, Ascoli V, Bosco D, Nardi F, D'Ambrosio F, Rubini A, Giacomelli L, Biffoni M, Filetti S, Durante C, Cantisani V. Ultrasonography scoring systems can rule out malignancy in cytologically indeterminate thyroid nodules. Endocrine. 2017;57(2):256-61.

25. Dima M, Pecce V, Biffoni M, Di Gioia CR, Tallini G, Biffoni M, Rosignolo F, Verrienti A, Sponziello M, Damante G, Russo D, Durante C. Molecular profiles of cancer stem-like cell populations in aggressive thyroid cancers. Endocrine. 2016;53(1):145-56.

26. Lamartina L, Grani G, Biffoni M, Giacomelli L, Costante G, Lupo S, Maranghi M, Plasmati K, Sponziello M, Trulli F, Verrienti A, Filetti S, Durante C. Risk stratification of neck lesions detected Sonographically during the follow-up of differentiated thyroid Cancer. J Clin Endocrinol Metab. 2016;101(8):3036-44.

27. Pasta V, Urciuoli P, D'Orazi V, Sottile D, Monti M, Redler A. Contralateral axillary metastases from breast cancer. Personal experience and review of literature. Ann Ital Chir. 2014;85(3):260-4.

28. Tartaglia F, Giuliani A, Tromba L, Carbotta S, Karpathiotakis M, Tortorelli G, Pelle F, Merola R, Donello C, Carbotta G, De Anna L, Conzo G, Sorrenti S, Ulisse S. Fine needle aspiration cytology of 650 thyroid nodules operated for multinodular goiter: a cyto-histological correlation based on the new Italian cytological classification (siapec 2014). J Biol Regul Homeost Agents 2016 Oct-Dec;30(4):1187-1193. PubMed PMID: 28078873.

29. Papale F, Cafiero G, Grimaldi A, Marino G, Rosso F, Mian C, Barollo S, Pennelli G, Sorrenti S, De Antoni E, Barbarisi A. Galectin-3 expression in thyroid fine needle cytology (t-FNAC) uncertain cases: validation of molecular markers and technology innovation. J Cell Physiol. 2013 May; 228(5):968-74

30. Baldini E, Sorrenti S, Catania A, Guaitoli E, Prinzi N, Mocini R, Nardi F, D'Armiento E, Bianchini M, Favoriti P, Di Matteo FM, Ruggieri M, De Antoni E, Ulisse S. Diagnostic utility of thyroglobulin measurement in the fine needle aspirates from cervical lymph nodes: a case report. G Chir. 2012 Nov-Dec;33(11-12):387-91.

31. Conzo G, Docimo G, Pasquali D, Mauriello C, Gambardella C, Esposito D, Tartaglia E, Della Pietra C, Napolitano S, Rizzuto A, Santini L. Predictive value of nodal metastases on local recurrence in the management of differentiated thyroid cancer. Retrospective clinical study. BMC Surgery. 2013; 13(Suppl 2):1-6.

32. Pezzolla A, Docimo G, Ruggiero R, Monacelli M, Cirocchi R, Parmeggiani D, Conzo G, Gubitosi A, Lattarulo S, Ciampolillo A, Avenia N, Docimo L, Palasciano N. Incidental thyroid carcinoma: a multicentric experience. Recenti Prog Med. 2010;101:194-8.

33. Calò PG, Conzo G, Raffaelli M, Medas F, Gambardella C, De Crea C, Gordini L, Patrone R, Sessa L, Erdas E, Tartaglia E, Lombardi CP. Total thyroidectomy alone versus ipsilateral versus bilateral prophylactic central neck dissection in clinically node-negative differentiated thyroid cancer. A retrospective multicenter study. Eur J Surg Oncol. 2017;43:126-32.

34. Buerba R, Roman SA, Sosa JA. Thyroidectomy and parathyroidectomy in patients with high body mass index are safe overall: analysis of 26,864 patients. Surgery. 2011;150:950-8.

35. D'Orazi V, Ortensi A. Use of optical magnification and microsurgical technique in general surgery. Australas Med J. 2017:10:989-92.

36. Gambardella C, Polistena A, Sanguinetti A, Patrone R, Napolitano S, Esposito D, Testa D, Marotta V, Faggiano A, Calò PG, Avenia N, Conzo G. Unintentional recurrent laryngeal nerve injuries following thyroidectomy: is it the surgeon who pays the bill? Int I Surg. 2017:41(Suppl 1):S55-9.

37. Attie JN, Khafif RA. Preservation of parathyroid glands during total thyroidectomy. Improved technic utilizing microsurgery. Am J Surg. 1975; 130:399-404.

38. Cavallaro G, Taranto G, Chiofalo MG, Cavallaro E. Usefulness of microsurgery to isolation of recurrent laryngeal nerve and parathyroid during thyroidectomy operations. Microsurgery. 1998;18:460-1.

39. Pata G, Casella C, Mittempergher F, Cirillo L, Salerni B. Loupe magnification reduces postoperative hypocalcemia after total thyroidectomy. Am Surg. 2010:76:1345-50

40. Ortensi A, Panunzi A, Trombetta S, Cattaneo A, Sorrenti S, D'Orazi V. Advancement of thyroid surgery video recording: a comparison between two full HD head mounted video cameras. Int J Surg. 2017;41(Suppl 1):S65-9.

Ready to submit your research? Choose BMC and benefit from:

- fast, convenient online submission

- thorough peer review by experienced researchers in your field

- rapid publication on acceptance

- support for research data, including large and complex data types

- gold Open Access which fosters wider collaboration and increased citations

- maximum visibility for your research: over $100 \mathrm{M}$ website views per year

At $\mathrm{BMC}$, research is always in progress.

Learn more biomedcentral.com/submissions 